
artigo $]$

[ LUCIANA CRIVELLARI DULCI ]

Doutora em Sociologia pela Universidade Federal de Minas Gerais, professora e pesquisadora na Universidade Federal de Ouro Preto, em Minas Gerais. Membro da Associação Brasileira de Estudos e Pesquisas em Moda (ABEPEM/BRASIL) e do Comitê Científico do Colóquio de Moda (Brasil).

E-mail: ludulci@gmail.com

\section{Globalização, moda e a cultura do consumismo}

Globalisation, fashion and the culture of consumerism

[resumo] Este artigo é um ensaio teórico que tem como proposta tecer uma reflexão sociológica a respeito do tempo presente, com suas tendências globalizadoras, e analisar como essas características influenciam a moda deste tempo e a relação com o consumo.

globalização; moda; cultura; consumismo.

[abstract] This article is a theoretical essay that proposes to develop a sociological reflection on the characteristics of the present time, with its globalising trends, and analyze how these characteristics influence the fashion of this time and the relationship with the consumer.

[keywords] globalisation; fashion; culture; consumerism. 
Para realizar a análise das tendências globalizadoras e suas consequências sobre a moda e as relações de consumo na contemporaneidade, nos debruçamos sobre os textos de Mike Featherstone e Antony Giddens, resenhando suas teorias para levantar como eles pensaram este tempo. 0 estudo segue mapeando os delineamentos da moda e suas especificidades contemporâneas, ensaiando algumas inferências analíticas para ajudar a compreender este momento social.

Featherstone, em A globalização da complexidade, expõe duas principais concepções sobre o pós-modernismo que, segundo alguns analistas, caracterizam o tempo presente. Uma das vertentes percebe o tempo presente como pósmoderno, em um processo cultural que, tendo ultrapassado a modernidade, tende a inviabilizar o projeto moderno de "[...] submeter a vida social à ordem e ao progresso" (FEATHERSTONE, 1996, p. 109). A outra perspectiva, na qual o próprio autor se inclui, percebe o pós-modernismo como uma dimensão cultural associada aos desenvolvimentos da sociedade contemporânea. Nesta última vertente, 0 tempo presente é retratado como portador de tendências globalizadoras intrínsecas, que provocaram, nos últimos tempos, o aumento do fluxo de informações, imagens, pessoas e todas as coisas em geral. Contudo, para Featherstone, esse fenômeno não levou a uma uniformidade internacional, homogeneizando todo o mundo. 0 localismo e a complexidade cultural se mantêm e, em alguns casos, são até reforçados, em contraposição a esta tendência globalizante.

A extensão da competição em escala mundial, no mundo contemporâneo, dá origem a uma crescente desregulação e desorganização, de modo que as nações e coletividades vão se enfraquecendo cada vez mais sob o impacto da expansão do fluxo de dinheiro, mercadorias, tecnologias, informações e imagens. Atentar para a metáfora dos fluxos, neste momento em que vivemos, de capitalismo globalizado, é de grande importância, pois esses fluxos são entendidos como forças de descentramento, deslocamento no espaço e desmaterialização, promovendo a fragmentação cultural e a transposição dos valores. Dessa maneira, a globalização, e com ela o pós-modernismo, seriam uma consequência da modernidade.

Para Featherstone, no pós-modernismo estão associados objetos portadores de signos, estetização da vida cotidiana, fragmentação das hierarquias simbólicas e uma cultura de consumismo que vai além dos produtos, passando a incluir, com importância igual ou superior aos produtos, os signos. Featherstone acredita que a cultura pós-moderna transmite uma sensação de perturbação e fragmentação cultural, decorrente de um descentramento desta cultura em relação ao que era na modernidade. A modernidade expressa uma ordenação e coerência, em um projeto universalizante que não existe mais no tempo em que vivemos e que, portanto, parece ter uma urgência de diagnóstico. Esse processo de fragmentação e colapso cultural das hierarquias simbólicas tem sua origem mais na consciência de uma modificação do valor do poder simbólico e do capital cultural do Ocidente do que na passagem para uma nova etapa da história, que seria a "pós-modernidade". A ênfase na fragmentação e no sincretismo cultural se apresenta, então, em contraposição às noções de identidade e cultura imobilizadas, como estruturas imutáveis nas sociedades.

0 pós-modernismo acaba com a certeza de uma construção teórica central, segura, vista como mais elevada e mais avançada em termos reais e simbólicos, como é o projeto da modernidade dos centros ocidentais, para trazer uma mistura consciente de tradições e cruzamentos de fronteiras, trazendo influências de culturas antes vistas como marginais, de fronteira, para o centro da cultura complexa global, valorizando e respeitando a cultura particular e local. Desta forma, as concepções antes consideradas dominantes vêm sendo questionadas e muitos pressupostos universais são agora vistos como decorrentes de um tempo e um lugar limitados. (FEATHERSTONE, 1996, p. 119) 
Para Featherstone (1996, p. 107), "[...] não se deve compreender o pós-modernismo apenas como uma mudança localizada numa época, ou como uma nova etapa do capitalismo". 0 tempo em que vivemos não rompeu totalmente com o equilibrio de forças e as interdependências que vinculam as pessoas na modernidade. Contudo, o processo de globalização tem ajudado a corroer a suposta integridade e unidade dos estados-nações. 0 termo pós-modernismo sugere, assim, uma superprodução de bens culturais, difícil de controlar e ordenar, que desestabiliza as hierarquias simbólicas existentes. Com o desenvolvimento da cultura de consumo de massa, aumentou não apenas o consumo de bens, mas também o consumo de imagens, signos e experiências.

0 desenvolvimento e a difusão, a partir de 1960, de novas tecnologias de comunicação ampliam ainda mais as noções de tempo-espaço social, com a redução das distâncias físicas e uma maior percepção da simultaneidade, de ter a experiência de novos lugares e novas sensações.

0 argumento de Featherstone aproxima-se da reflexão de Giddens (19911, p. 59), que propõe: "[...] se não vivemos ainda num universo social pós-moderno, já podemos perceber a emergência de modos de vida e formas de organização social que divergem daquelas criadas pelas instituições modernas". Contudo, Giddens entende a modernidade com base em outro modelo explicativo. Esse autor utiliza categorias e conceitos inter-relacionados, por ele forjados, para compreender o momento atual em que vivemos, denominado por ele como alta-modernidade ou modernidade radicalizada. A emergência das instituições modernas, caracterizadas pelo dinamismo e por um escopo globalizante, que explicam a natureza de suas descontinuidades em relação às culturas tradicionais, é pensada por meio de conceitos como a separação tempo -espaço, o desencaixe das relações sociais - justamente em virtude da separação de tempo-espaço - e a reflexividade, entendida como revisão e reflexão constantes sobre as práticas da vida social moderna.

0 dinamismo e a tendência globalizante das instituições modernas, não apenas em relação à tecnologia, conectam o local e o global de forma impensada nas sociedades tradicionais. Justamente o distanciamento na relação tempo-espaço e o desencaixe (que tem como exemplos as fichas simbólicas e os sistemas peritos, ambos dependentes da confiança dos indivíduos) - entendido como deslocamento das relações sociais de contextos locais de interação e sua reestruturação através de extensões indefinidas de tempo-espaço - promovem encontros e trocas entre espaços distantes, aproximando os espaços locais e provocando um sentimento de simultaneidade de processos.

\section{Tempo presente e seu escopo globalizante}

0 momento atual não é chamado de pós-modernismo por Giddens (1991). Pós-modernismo, para este autor, é a reflexão estética sobre a natureza da modernidade; estilos ou movimentos no interior da literatura, artes plásticas e arquitetura. 0 tempo presente, que ainda não alcançou a pós-modernidade, contudo, tem nítidas diferenças das condições constituintes do projeto de modernidade, pois não se pode defender com certeza nenhuma versão de progresso com base em uma direção evolucionária. A história, hoje, é feita de uma pluralidade de histórias e não traz apenas a visão ocidental como única e dominante. Ainda assim, as instituições fundantes da modernidade - promovidas grandemente pelo capitalismo e o sistema de estados-nações - continuam a vigorar, com a diferença que, neste momento, a modernidade busca cada vez mais entender a si mesma.

Em vez de estarmos entrando num período de pós-modernidade, estamos alcançando um período em que as consequências da modernidade estão se tornando mais radicalizadas e universalizadas do que antes. Além da modernidade, devo argumentar, podemos perceber os contornos de uma ordem nova e diferente, que é "pós-moderna"; mas isto é bem diferente do que é atualmente chamado por muitos de "pós-modernidade". (GIDDENS, 1991, p. 12-13) 
As instituições modernas criaram oportunidades de uma existência segura e gratificante por um lado, mas, de outro, o desenvolvimento das forças produtivas trazem um potencial destrutivo sobre o meio ambiente e a política. A tradição que antes existia oferecia uma segurança baseada na fé, embora as condições gerais da sociedade pudessem oferecer muitos riscos aos indivíduos. Essa situação é substituída por uma confiança nas interações sociais modernas, com o objetivo de minorar esses riscos que, na modernidade, são calculadamente menores do que nas sociedades pré-modernas, em que os indivíduos têm consciência dos perigos e, por isso, se engajam para suportar as consequências.

Nesse sentido, a modernidade desenvolve sistemas abstratos que controlam a vida dos indivíduos de alguma maneira, e dos quais não se têm nenhum ou pouco controle, já que não se detém o conhecimento total sobre o funcionamento deles. Dentre os sistemas abstratos considerados por Giddens, pode-se citar o sistema bancário, a informática, o funcionamento de um avião etc. Para fazer uso desses sistemas abstratos precisamos confiar em especialistas, peritos nos sistemas. Então, Giddens elaborou os conceitos de fichas simbólicas e sistemas peritos, que são mecanismos de desencaixe, pois dependem da confiança, que substituiu, na modernidade, os valores da tradição. Desencaixe é o "[...] deslocamento das relações sociais de contextos locais de interação e sua reestruturação através de extensões indefinidas de tempo-espaço" (GIDDENS, 1991, p. 29).

Sistemas peritos, pontua Giddens (1991, p. 35), são "[...] sistemas de excelência técnica ou competência profissional que organizam grandes áreas dos ambientes material e social em que vivemos hoje". Estes podem ser considerados mecanismos de desencaixe porque estão imbuídos de códigos e símbolos que agregam e produzem "fé", criando áreas de segurança, importantes para a perpetuação da vida cotidiana. São forças reguladoras que ampliam as relações sociais para além de seu contexto imediato. Por fichas simbólicas, Giddens (1991, p. 30-32) define os "meios de intercâmbio que podem ser 'circulados' sem ter em vista as características específicas dos indivíduos ou grupos que lidam com eles em qualquer conjuntura particular", como os meios de legitimação da política e o dinheiro. 0 dinheiro é um meio de distanciamento tempo-espaço, possibilitando a realização de transações entre agentes amplamente separados no tempo e no espaço - um meio de troca que relativiza o conteúdo dos bens e serviços, substituindo-os por um padrão impessoal.

A natureza dinâmica da modernidade e seu escopo globalizante envolvem principalmente três fontes características, segundo a perspectiva de Anthony Giddens: 1. a separação do tempo-espaço e suas recombinações; 2 . o desencaixe dos sistemas sociais e 3. ordenação e reordenação reflexiva das relações sociais, afetando as ações dos indivíduos e grupos. 0 que se poderia dizer sobre a teoria de ambos os autores a respeito do momento em que a sociedade hoje se encontra é que grande parte do que é chamado de condições da pós-modernidade, na verdade, são características associadas à própria modernidade.

A diferença entre as condições que originaram a modernidade e o tempo presente é que vários desses elementos, apontados ora por Featherstone, ora por Giddens (1991), quais sejam, "volatilidade dos signos", "fragmentação cultural", "confusão das identidades", "estetização da vida cotidiana", "consumismo em massa de imagens e signos", "separação tempo-espaço", "desencaixe das relações", "reflexividade" ou mesmo o desenvolvimento de sistemas de confiança em um tempo cada vez mais instável, estão mais radicalizados e, portanto, estão sendo mais percebidos na vida das pessoas. Contudo, tanto Featherstone quanto Giddens não acreditam que as condições desse tempo inauguram uma nova forma de ordenamento social.

\section{Sociedade contemporânea, produção cultural e consumo de massa}

0 consumismo do tempo presente é um conceito diferente do consumo das sociedades modernas. Este último, o consumo moderno, era um dos meios de atender a 
certos tipos de necessidades (inclusive supérfluas), adquirindo-se produtos ou serviços que resolveriam tais precisões, por meio de relações de troca entre produtos ou serviços e moeda. Retomando Featherstone, o consumismo compreende, além do consumo dos produtos, também o consumo da imagem social e do valor simbólico que têm esses produtos. Essa "intensificação" da forma de como se apropria de um produto, do consumo ao consumismo, surge a partir das transformações sociais que fizeram emergir a cultura e o consumo de massa.

0 surgimento da sociedade de massa - sociedade esta que tem suas decorrências culturais genericamente designadas por "cultura de massa", a cultura produzida e consumida na sociedade de massa - relaciona-se à emergência da sociedade capitalista industrial, que tem como marcos de seu aparecimento a Revolução Francesa e a Revolução Industrial, bem como, de forma mais ampla, o desenvolvimento das relações de mercado e a urbanização crescente das cidades ocidentais.

Os elementos culturais dessa ordem social caracterizaram-se, progressivamente, por uma produção em nível industrial de uma gama extensa de produtos, ligados principalmente às formas de lazer, mas também à moda, aos espetáculos públicos, à música, à literatura, ao cinema e, posteriormente, à televisão. A designação "produto cultural", utilizada amplamente pelos estudiosos desta problemática, já vem intrinsecamente condicionada por sua existência urbano-industrial. Produto é o elemento final de uma cadeia produtiva. Acredita-se que houve um decréscimo paulatino da autonomização cultural e da criação artesanal das obras culturais, sendo estas substituídas por produtos de fabricação mais fácil, menos demorada, menos dispendiosa e facilmente reproduzivel, já que a questão de ordem é o cálculo econômico: são produzidas para gerarem um lucro maior do que a produção artesanal.

Sobre a cultura de massa, não se pode dizer sublimação das individualidades ou imposição de valores e práticas por agentes totalmente externos e alheios às pessoas. As próprias pessoas, no processo de socialização e compartilhamento de símbolos, valores e práticas, criam os mesmos elementos que são absorvidos e difundidos pelas instituições sociais, justamente por serem aceitos pelos indivíduos. 0 que se pode dizer é um aproveitamento por parte do sistema capitalista de produção desses mesmos símbolos, valores e práticas, em "embalagens" bem concebidas, com o intuito de vender em grande quantidade e para um público vasto. Um cuidado maior seria prudente ao afirmar que os produtores da cultura de massa percebem demandas junto ao público que são rapidamente produzidas em modelos com um objetivo comercial voltado para consumidores incapazes de entender que estão sendo manipulados'. Os objetos consumidos por esse público provavelmente representam ideias e desejos que foram primeiramente manifestados pelo próprio público.

0 consumo cultural nas sociedades de massa deve ser pensado em um processo dialético, no qual o sistema de produção cultural influencia e molda os desejos de consumo, criando, em certa medida, o consumidor de massa, mas a produção cultural não deixa de ser determinada pelo próprio mercado, pelas próprias necessidades destacadas pelos consumidores. A capacidade de autosseleção do consumidor faz com que este realize suas escolhas mais fielmente às suas identificações, projeções e a seu gosto do que propriamente por um modelo imposto. A ideia de Edgar Morin (2002) é que não há um fluxo unilateral de informações partindo dos meios de difusão da cultura de massa em relação ao consumidor. Existem propostas de consumo, veiculadas pelas formas simbólicas da cultura de massa, mas sem imposição, já que as escolhas são facultadas aos consumidores. Estes identificam-se com posturas ideológicas que transmitam mensagens familiares a suas crenças, mesmo que isso aconteça após um primeiro momento de identificação de seu gosto. Sobre a formação do gosto, Pierre Bourdieu (1983, p. 128) tem o seguinte pensamento: 
coisa que lhe traga prazer, ao seu gosto, o espectador descobre o que deseja e o que tinha vontade de dizer ou expressar. Mas que, por ainda não sabê-lo, ficava impossibilitado de manifestar-se.

Complementarmente, pode-se dizer que o mercado consumidor, na sociedade contemporânea, não se contenta em depositar seus produtos em prateleiras e esperar a resposta do consumidor para saber se vai ter aceitabilidade ou não. Pesquisas de opinião, atualmente cada vez mais sofisticadas, são realizadas para avaliar as necessidades e as expectativas do consumidor, sua predisposição a produtos novos ou a novos formatos, materiais e embalagens de produtos já disponíveis no mercado. Portanto, se um produto está sendo oferecido ao consumo, certamente é porque se constatou, por meio de informações advindas do público consumidor, a sua provável aceitação. Os meios de comunicação de massa colhem ideias e informações de seu público consumidor da mesma forma que este se reporta aos ícones da cultura de massa e/ou aos líderes de opinião - que frequentemente estão associados aos veículos de difusão de informação ou são pessoas próximas ao seu universo - para se orientarem em relação ao consumo.

Os modos de vestir, as "modas" e seus costumes fazem parte dos usos que integram as relações sociais mais elementares das sociedades ao longo dos tempos e períodos históricos diferentes. Constituem-se nas formas escolhidas e criadas para se vestir, assim como se faz em outras escolhas e modos de vida, como técnicas de construção de habitações ou culinária, por exemplo. Considerando a moda como um fenômeno simbólico, ela poderia ser definida como um uso social que inclui instruções orientadoras do comportamento humano. Essas instruções se colocam de fora da cultura constituída em direção aos atores desta, e são estes mesmos atores, simultaneamente, os produtores dela - por criarem modos de vestir que são difundidos socialmente -, e produtos constituídos pelas práticas culturais adotadas em qualquer campo e aqui, especificamente, na moda.

A moda no vestuário seria ainda um resultado das ações reciprocamente referidas dos indivíduos que criam, produzem e usam as roupas, em ações orientadas umas em direção às outras, formando uma rede de interferências mútuas. A moda não é um condicionamento a priori externo aos ditames e às orientações sobre os hábitos de vestuário dos indivíduos. Os indivíduos criam e usam roupas conforme suas subjetividades e interpretação do mundo em que vivem, podendo fazer e refazer suas escolhas sem estarem sujeitos a nenhum tipo de cultura/moda deterministas e universais.

\section{Moda global e a cultura do consumismo}

0 início da produção em massa no vestuário de roupas prontas para vestir - referidas também como prêt-á-porter (francês) ou ready-to-wear (inglês) - demarca 0 princípio de um período histórico que não mais se pode explicar pelo modelo teórico da moda clássica, aristocrática, imposta por estilistas e pela elite que encomendava seus produtos artesanais, a alta-costura. A produção em larga escala de roupas permitiu que mais classes de pessoas pudessem adquirir tais roupas, já que estas são mais baratas do que as de outrora, produzidas artesanalmente. Com um maior acesso às roupas, a partir da industrialização de sua produção, observa-se, progressivamente, maior manifestação pública, nos espaços de sociabilidade, de diferentes valores e estilos de vida também pelo vestuário, o que antes não acontecia.

As manifestações de moda atuais evidenciam tendências múltiplas na composição do vestuário, demostrando, muitas vezes, influências abissalmente contraditórias. São elementos oriundos da contracultura urbana de outras décadas, como os hippies (década de 1960), os punks (década de 1970), da música de som pesado como o heavy metal (década de 1980); de culturas não ocidentais consideradas exóticas, como as africanas, indiana e japonesa, e, ainda, reedições de elementos do vestuário ocidental 
consagrados em modas que vigoraram em outras décadas do século XX. Esse século de grandes transformações econômicas e políticas é também muito representativo em termos de moda no vestuário, pois as mudanças foram imensas e traziam realmente novidades, a cada década, do que era antes produzido e utilizado. 0 que se verifica hoje é a coexistência de variados grupos de estilo, com tipos e hábitos vestimentares distintos, embora muitas vezes com influências interpenetradas.

Isso sugere também que a difusão da moda contemporânea não acontece sempre de acordo com o modelo conhecido como tricle-down, ou seja, proveniente das classes economicamente mais abastadas em direção às classes menos providas de recursos. Atualmente, de acordo com Massimo Baldini (2006), a difusão ou divulgação de um estilo novo na moda pode acontecer horizontalmente: em grupos de estilo distintos, mas em um mesmo padrão de renda; entre grupos com padrões de renda distintos, mas com estilos de vida similares; por grupos de contracultura ou culturas consideradas exóticas ou "marginais" etc. Todas essas possibilidades desconstroem a ideia de uma imitação entre classes hierarquicamente dispostas por fatores majoritariamente econômicos, sobretudo como indicado nas análises mais economicistas desse fenômeno, que apresentam uma imitação sempre oriunda das classes menos abastadas em direção às mais abastadas. 0 objetivo de obtenção de distinção pode ainda existir nos dias atuais, mas as elites econômicas não são percebidas como as únicas classes especiais e, portanto, principais orientadoras de estilo no vestuário, apenas as mais providas de recursos financeiros.

A moda contemporânea sugere uma valorização de outras classes, nas quais questões culturais parecem interferir até mais no desejo de imitação do que propriamente o fator econômico. Por outro lado, a moda atual faz parte de um contexto social que abriga mais largamente discussões sobre a globalização, que progressivamente parece buscar pela homogeneização em aspectos diversos dos padrões de comportamento e atitude no vestuário. Influências das modas verificadas em grupos de expressão distintos e alternativos ao grupo de moda anteriormente concebido como dominante são absorvidas paulatinamente por essa moda socialmente legitimada, central na sociedade. Na sociedade contemporânea, fortemente orientada pelo consumismo e consumo de massa, os grupos de "contramoda" ou "antimoda" acabam por ter suas manifestações de moda, a princípio identificadas como singulares e exclusivas, incorporadas no movimento social análogo (anteriormente) dominante.

Absorver esses elementos, antes distintivos de um grupo antagônico, enfraquece a iniciativa da oposição e fortalece a posição de dominante da moda central, que progressivamente vai incorporando o máximo de elementos possível como matéria-prima para a criação de suas tendências, o que no tempo presente representa também atingir um público mais amplo, com a difusão da cultura de massa.

A regeneração da moda, hoje, não parece ser propulsionada pelo movimento de defesa dos estabelecidos e bem providos economicamente, no intuito de evitar a mediocrização dos modos vestimentares usados por classes "inferiores". 0 consumismo parece ser, atualmente, a principal mola propulsora de um movimento que necessita de regeneração constante, justamente para estimular mais vendas, aquisições de produtos muito similares em curto intervalo de tempo e um consumo crescente dos usuários em massa. 0 fenômeno do fast-fashion (CIETTA, 2010) é o melhor exemplo para se entender a força do consumismo como gerador de novas modas, em períodos curtíssimos de tempo, em uma produção de vestuário de baixa qualidade.

0 momento presente, que coincide historicamente com o fim do século XX e início do século XXI, apresenta uma diferença em relação à moda tradicional. Movimentos outrora marginais à concepção dominante de moda convivem pacificamente com influências "tradicionais" da moda que já foi a única dominante, ocorrendo uma interpenetração de influências entre tendências antes tomadas como opostas. Essa incorporação de elementos da contramoda no movimento central da moda servem a uma disseminação ainda maior do fenômeno da moda e à estimulação de um tipo específico de consumo, o consumo de massa. 0 movimento de apropriação da contramoda pela moda, em parte, ocorreria por ser o fenômeno 
moderno da moda inserido em um esquema de produção industrial, fortemente condicionado por seu viés econômico. Esse aspecto sugere um aproveitamento até de formas que se manifestam contrariamente ao sistema central da moda, revertendo o negativo em positivo e lucrativo empreendimento.

Não se pode deixar de destacar que, sob o ponto de vista econômico, questões emergentes no estudo das sociedades, como a propagação do consumo em tempos do capitalismo avançado - o consumismo -, sugerem uma "facilidade" em incorporar manifestações antagônicas ao sistema, nesse mesmo sistema centralmente reconhecido. Isso se dá como forma de banalizar e minorar as expressões de oposição, neste caso, especificamente, as modas alternativas de antes, bem como de estimular ainda mais o consumo já intrinsecamente associado à existência de modismos. Transformam-se, assim, elementos de contestação em parte constitutiva do fenômeno de moda, que passa a incorporar todas as manifestações em uma existência plural.

0 consumismo é então uma categoria-chave para se pensar a moda no tempo presente. Esta é uma das principais diferenças em relação aos contextos anteriores de manifestação de moda. Ainda que o consumo tenha estado sempre presente na relação dos indivíduos com a produção de sua apresentação pessoal, o momento histórico compreendido desde meados do século XX e início do XXI é fortemente associado ao crescimento da preocupação sociológica com a questão do consumo ${ }^{2}$ e às transformações sociais que inauguraram uma cultura de consumismo de massa. E a moda atual institui uma correspondência cada vez maior com as necessidades e os espaços de consumo contemporâneos.

\section{NOTAS}

${ }^{[1]}$ Ideia difundida originalmente pela Teoria Crítica, a exemplo de autores como Theodor Adorno, Max Horkheimer e Walter Benjamin

[2] Ver a exemplo: Canclini (1999), Campbell (2001), Baudrillard (1995), Debord (1997), Featherstone (1995), Rocha (1995), dentre outros.

\section{REFERÊNCIAS}

BAUDRILLARD, Jean. A sociedade de consumo. Rio de Janeiro: Elfos, 1995.

BALDINI, Massimo. A invenção da moda: as teorias, os estilistas, a história. Lisboa: Edições 70, 2006.

BOURDIEU, Pierre. A metamorfose dos gostos. In: Questões de sociologia. Rio de Janeiro: Marco Zero, 1983.

CAMPBELL, Colin. A ética romântica e o espírito do consumismo moderno. Rio de Janeiro: Roxo, 2001.

CANCLINI, Nestor Garcia. Consumidores e cidadãos: conflitos multiculturais da globalização. Rio de Janeiro: UFR, 1999.

CIETTA, Enrico. A revolução do fast-fashion: estratégias e modelos organizativos para competir nas indústrias híbridas. São Paulo: Estação das Letras e Cores, 2010.

DEBORD, Guy. A sociedade do espetáculo. Rio de Janeiro: Contraponto, 1997.

FEATHERSTONE, Mike. A globalização da complexidade: pós-modernismo e cultura de consumo. RBCS ano 11, n. 32, outubro de 1996.

Cultura de consumo e pós-modernismo. São Paulo: Nobel, 1995.

GIDDENS, Anthony. As consequências da modernidade. São Paulo: Editora UNESP, 1991

MORIN, Edgar. Cultura de massas no século XX. Rio de Janeiro: Forense Universitária, 2002. v. 2.

ROCHA, Everardo. A sociedade do sonho: comunicação, cultura e consumo. Rio de Janeiro: Mauad, 1995. 